\title{
Proposed Protocol for Risk Assessment and Stratification
}

\section{Teófila Vicente-Herrero ${ }^{1,2^{*}}$, Victoria Ramírez Iñiguez de la Torre ${ }^{1,3}$, Teresa del Campo Balsa1,4, Luis Reinoso Barbero1,5,6, Alejandro Fernández Montero ${ }^{1,7}$, Juan Carlos Rueda Garrido ${ }^{1,8}$}

\author{
${ }^{1}$ Asociación Española de Especialistas en Medicina del Trabajo, Madrid, Spain \\ ${ }^{2}$ Occupational Health and Safety Services of Correos, Valencia, Spain \\ ${ }^{3}$ Occupational Health and Safety Services of Correos, Albacete, Spain \\ ${ }^{4}$ Department of Occupational and Prevention at University Hospital Fundación Jiménez Díaz, Universidad Autónoma de Madrid, \\ Madrid, Spain \\ ${ }^{5}$ Occupational Medicine Service Grupo Banco Santander, Madrid, Spain \\ ${ }^{6}$ Faculty of Health Sciences, Universidad International de la Rioja, La Rioja, Spain \\ ${ }^{7}$ Department of Occupational Medicine, Universidad de Navarra, Navarra, Spain \\ ${ }^{8}$ SABIC Medical Services, Cartagena, Spain \\ Email: *vicenteherreromt@gmail.com
}

How to cite this paper: Vicente-Herrero, T., de la Torre, V.R.I., del Campo Balsa, T., Barbero, L.R., Montero, A.F. and Garrido, J.C.R. (2020) Proposed Protocol for Risk Assessment and Stratification. Occupational Diseases and Environmental Medicine, 8, 99-110.

https://doi.org/10.4236/odem.2020.83008

Received: July 1, 2020

Accepted: August 2, 2020

Published: August 5, 2020

Copyright $\odot 2020$ by author(s) and Scientific Research Publishing Inc. This work is licensed under the Creative Commons Attribution International License (CC BY 4.0).

http://creativecommons.org/licenses/by/4.0/

(c) (i) Open Access

\begin{abstract}
Introduction: COVID-19 disease is a highly contagious viral infection caused by the SARS-CoV-2 coronavirus. There is growing interest in Public Health and Occupational Health in identifying the COVID-19 prognostic factors, needed to stratified patients by risk being necessary to consider occupational variables as well as individual and clinical factors of the workers. Objective: The aim of this study was to perform a tool to identify the more vulnerable workers for COVID-19 that will be useful to value their work limitations. Methods: A review of medical literature about the vulnerability for COVID-19 is taken into account occupational risks and occupational preventive measures. Results: It is proposed an index of vulnerability criteria for COVID-19 in workers based on quantifying individual characteristics, pre-existing medical conditions and its control, high risk of occupational exposure, and prevention and protection strategies in the workplace. The final result is stratified into three degrees of vulnerability that will serve to propose the most appropriate preventive measures. Conclusion: This proposal protocol assesses about the vulnerability for COVID-19 infection in workers to help decide the preventive management at workplace in this pandemic situation.
\end{abstract}




\section{Keywords}

COVID-19, Vulnerability, Occupational Health, Occupational Medicine

\section{Introduction}

SARS-CoV-2 pandemic (COVID-19) has generated a growing interest in Public Health, with the urge to define individual risk factors, in order to detect patients who could progress to severe or life-threatening illnesses. In the field of Occupational Health, it is necessary to stratified workers according to their risk or vulnerability, taking into account not only the classical clinical factors but also occupational-related variables and socio-demographic factors [1].

The job characteristics, and how the worker interacts with other people or other workers, can be translated into an increased risk of infection, making the worker a potential transmission of the virus in his community. Therefore, an early detection of outbreaks in work-environments, by assessing and quantifying the risk of contagious in a specific high risk workplace or occupational group, can help improve risk management in Public and Occupational Health and can be useful in preventing subsequent COVID-19 outbreaks. The work-environment is key to health interventions, which could protect both workers and the general population [2].

A worker's vulnerability is defined as the probability of being affected by a substance or risk greater than the normal probability based on age and sex, either as a result of a higher susceptibility to infection or a higher level of exposure. In COVID-19 a worker high vulnerability will include a greater risk of infection and a greater probability of serious consequences in case of COVID-19 infection [3].

The concept of COVID-19 vulnerability is changeable. A worker might not be considered as vulnerable at the beginning of the pandemic, but he may become vulnerable due to health, social or job-changes. Age and previous health problems, including mental problems and comorbidities are considered classical clinical risk factors [4]. Previous studies have estimated the risk for different occupations [5], including in some studies, the risk evaluation of up to 100 different work-environments, taking into account three aspects: physical contact, proximity and exposure to the disease [6].

The objective of this work is to establish criteria to assess worker vulnerability against COVID-19 infection and to quantify them to establish different levels of vulnerability. Vulnerability score will be useful to apply efficiently the appropriate preventive measures.

\section{Methods}

Before the inclusion of variables in the tool, a scientific literature review was performed For the bibliographic review and selection of the literature, an ex- 
haustive search of the COVID-19 concept and its relationship with the world of work is carried out, especially with the limitation of the worker, with the identification of the diseases related to the pandemic by their proper names. The search is carried out in Medline through the PubMed platform

(https://pubmed.ncbi.nlm.nih.gov/), free access and with extensive international coverage. The search period is limited to the last two years and specifically to the last year and also includes classified journal articles (editorials, originals, letters, reviews, clinical notes). Are used the search terms: "COVID-19 and workplace"; "COVID-19 and occupational risk"; "COVID-19 and occupational preventive measures"; "COVID-19 and Occupational Health"; "COVID-19 and "vulnerability" and "COVID-19 and chronic diseases".

Based on these reviews, we included in the protocol as elements to assess vulnerability: age, gender; previous comorbidities: diabetes, hypertension, obesity, smoking, cardiovascular diseases, coagulation disorders, chronic lung and liver disease, immune and autoimmune disorders, rheumatic diseases, inflammatory bowel diseases, cancer and major surgery; labor sectors and risk conditions and finally, the company's preventive situation: use of protective equipment, preventive training, health surveillance and job change options. Each of these aspects is scored to obtain a total result that is stratified into degrees of aspects.

\section{Protocol}

Based on the current evidence and acknowledging that we are in a constantly changing situation, the following evaluation parameters were included in this protocol.

\subsection{Individual Risk Factors Related to COVID-19 Vulnerability}

Age: people over 60 years old, especially those over 70 years old [7] are at higher risk.

Pregnancy: Current information on the impact of COVID-19 on pregnant women and fetuses shows that the probability of developing a serious clinical presentation is similar to that of the general population [8]. Nevertheless, it is necessary to be cautious in decision-making in pregnant working women, especially in high risk work sectors, such as health workers [9].

Gender: No clear differences have been detected between men and women. In Spain, the mortality rate in men is slightly higher [10] [11] [12].

\subsection{Previous Comorbidity to Related to Vulnerability COVID-19}

The presence of previous comorbidities has been clearly related to an increase in COVID-19 mortality rate [13]. Previous health conditions related to high risk include: 1) recent cancer diagnosis or cancer being treated at the time of infection [14]; 2) cardiovascular disease or coagulation disorders which have been associated with multiple direct and indirect cardiovascular complications [15] [16] or 3) diabetes which has been related to severe pneumonia and increased mortality [17] [18]; 4) obesity, especially if BMI $>40$ has also been related with 
higher mortality from COVID-19 [19] [20]. The most frequent comorbidities detected in severely infected patients are: hypertension, obesity and diabetes [21]; 5) moderate to severe asthma, has been associated with increased severity of infection and asthma nebulizer treatments should be avoided due to the risk of aerosolization [22] [23]; 6) other conditions include: chronic obstructive pulmonary disease, with rapid deterioration of lung function respiratory failure [24]; 7) tobacco use [25]; 8) chronic liver involvement. Hyperinflammatory reactions may contribute to the development of liver injury post COVID-19 [26] [27]; 9) immunity disorders have also been considered a risk factor for COVID-19 [28] including a very heterogeneous group with multiple underlying causes and degrees of immune alteration. Immunosuppression can be associated with a disease or secondary to prescribed treatments.

\subsection{Disease Control and Response to Prescribed Therapies}

To assess risk related to previous comorbidities, it is necessary to consider not only the disease itself, but also the level of disease control achieved over the last year, the need of therapeutic adjustments, the response to treatments, the number of acute-events or exacerbations requiring hospital admissions or urgent care visits, and sickness absence in the last year.

\subsection{Occupational Risks Related to COVID-19 Vulnerability}

When assessing worker vulnerability to COVID-19, some sectors are considered to be of highest risk, specifically those works in relation to public attention. The prevention measures placed against infection (collective and individual) must also be taken into account [29].

Healthcare workers. Recognized high risk. Rigorous preventive procedures and protective measures are recommended to guarantee the operation of the basic medical care system [30] [31] [32].

Social health workers. Including workers of nursing homes and social services, in this case, the high vulnerability of the people they work for and care for requires very rigorous control and monitoring of these workers [33].

Security Forces. In risk situations such as the current one, they may be in contact with symptomatic people and need specific strict protection measures.

\subsection{Preventive Management at the Workplace Related to COVID-19 Vulnerability}

It is an essential aspect in the assessment, the preventive management of companies and the integration of preventive measures in the organization.

Specific protocols for infection prevention and control within the company should be developed. Collective protection measures, such as separation of work places or barrier or protection elements to promote social distancing should be implemented. Individual protections such as face-masks, respirators, screens, or gloves, based on the knowledge of each different mask protective factor should be 
provided [34]. Areas for frequent hand washing and/or hydroalcoholic gel should be available. Preventive training actions and specific information sessions about the infection and the general preventive measures should be implemented by the company. Specific health surveillance and health actions based on the risk of contagion: assessment of vulnerable workers and detection and monitoring of cases and contacts. In workers when their own safety or third parties cannot be guaranteed with preventive measures, the option of a change in working conditions should be offered.

\section{Proposed protocol for risk assessment and stratification}

To quantify the risk and help support subsequent preventive decisions, we propose the methodology attached in Figure 1. The assigned score is shown in Tables 1-4 with an alternative option of using a computerized database to

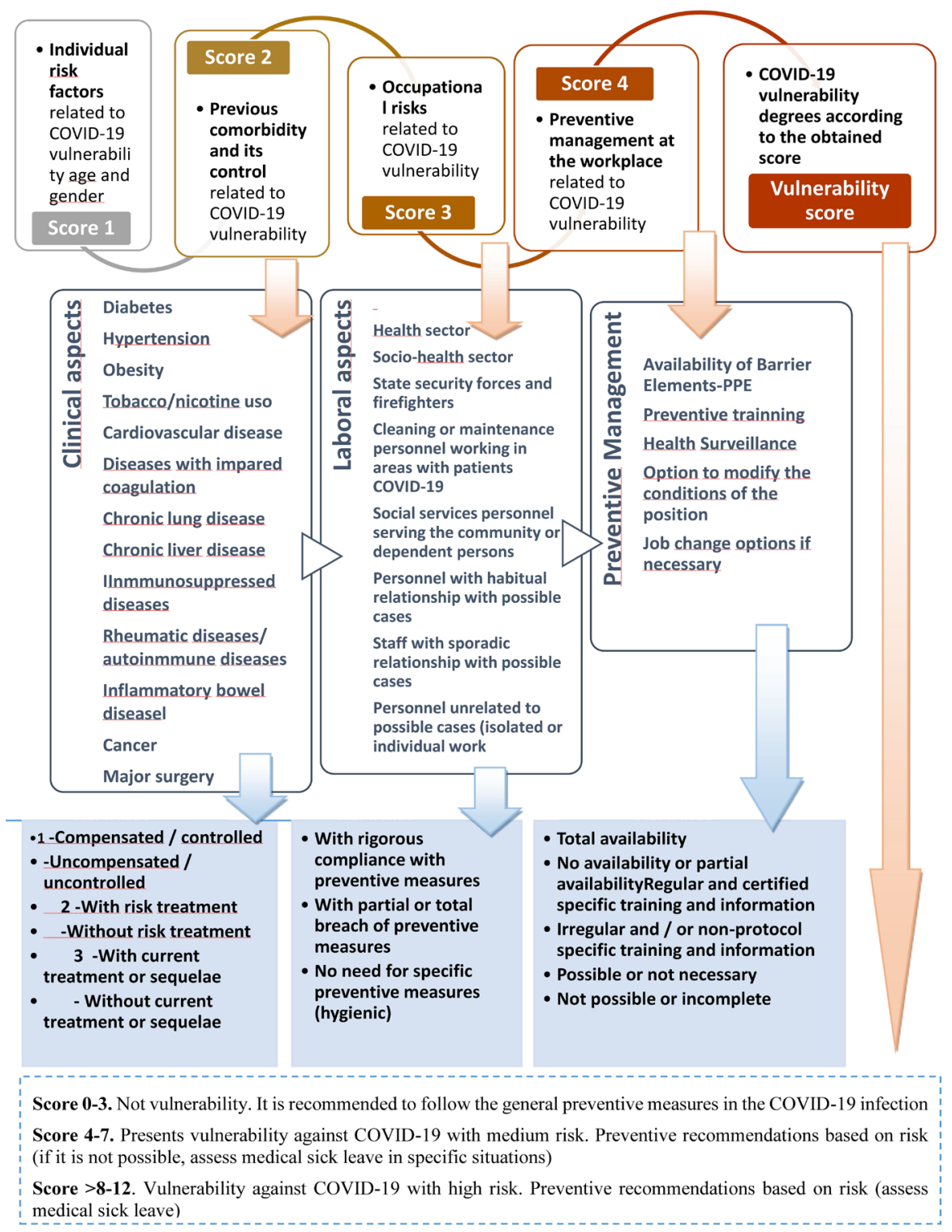

Figure 1. Spanish occupational medicine association. Vulnerability criteria guideline for COVID-19 in workers. 
Table 1. Individual risk factors related to COVID-19 vulnerability.

\begin{tabular}{clc}
\hline & & Score \\
\hline Age & $<60$ years & 0 \\
& $60-65$ years & 1 \\
& $\geq 66$ years & 2 \\
\multirow{2}{*}{ Gender } & Man & 0 \\
& Non-pregnant woman & 0 \\
& Pregnant woman & 1 \\
Total score of individual risk factors &
\end{tabular}

Table 2. Previous comorbidity and its control related to COVID-19 vulnerability.

\begin{tabular}{|c|c|c|}
\hline & & Score \\
\hline \multirow[t]{3}{*}{ Diabetes } & Not applicable & 0 \\
\hline & Compensated/controlled & 1 \\
\hline & Uncompensated/uncontrolled & 2 \\
\hline \multirow{3}{*}{ Hypertension } & Not applicable & 0 \\
\hline & Compensated/controlled & 1 \\
\hline & Uncompensated/uncontrolled & 2 \\
\hline \multirow[t]{3}{*}{ Obesity } & $\mathrm{BMI}<30$ & 0 \\
\hline & BMI 30 - 40 & 1 \\
\hline & $\mathrm{BMI}>40$ & 2 \\
\hline \multirow[t]{2}{*}{ Tobacco/nicotine use } & No & 0 \\
\hline & Yes & 1 \\
\hline \multirow[t]{3}{*}{ Cardiovascular disease } & Not applicable & 0 \\
\hline & Compensated/controlled & 1 \\
\hline & Uncompensated/uncontrolled & 2 \\
\hline \multirow{3}{*}{$\begin{array}{l}\text { Diseases with impaired } \\
\text { coagulation }\end{array}$} & Not applicable & 0 \\
\hline & Compensated/controlled & 1 \\
\hline & Uncompensated/uncontrolled & 2 \\
\hline \multirow[t]{3}{*}{ Chronic lung disease } & Not applicable & 0 \\
\hline & Compensated/controlled & 1 \\
\hline & Uncompensated/uncontrolled & 2 \\
\hline \multirow[t]{3}{*}{ Chronic liver disease } & Not applicable & 0 \\
\hline & Compensated/controlled & 1 \\
\hline & Uncompensated/uncontrolled & 2 \\
\hline \multirow[t]{3}{*}{ Immunosuppressed diseases } & Not applicable & 0 \\
\hline & Compensated/controlled & 1 \\
\hline & Uncompensated/uncontrolled & 2 \\
\hline \multirow{3}{*}{$\begin{array}{c}\text { Rheumatic/autoimmune } \\
\text { disease }\end{array}$} & Not applicable & 0 \\
\hline & Without risk treatment & 1 \\
\hline & With risk treatment & 2 \\
\hline \multirow{3}{*}{$\begin{array}{c}\text { Chronic inflammatory bowel } \\
\text { disease }\end{array}$} & Not applicable & 0 \\
\hline & Without risk treatment & 1 \\
\hline & With risk treatment & 2 \\
\hline
\end{tabular}




\section{Continued}

\begin{tabular}{cll}
\hline \multirow{2}{*}{ Cáncer } & Not applicable & 0 \\
& Without treatment or sequelae from $>1$ year & 1 \\
& With treatment up to $<1$ year & 2 \\
& With current treatment or sequelae & 3 \\
Not applicable & 0 \\
Wajor surgery & Without treatment or sequelae from $>1$ year & 1 \\
& With treatment up to $<1$ year & 2 \\
With current treatment or sequelae & 3
\end{tabular}

Table 3. Occupational risks related to COVID-19 vulnerability.

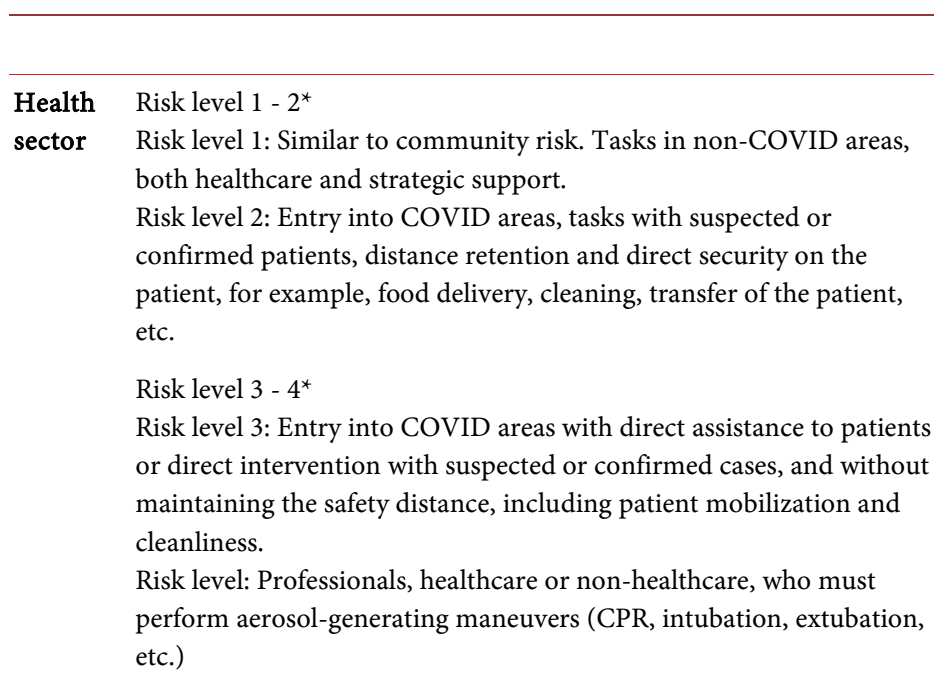

Social health workers. Including workers of nursing homes and social services

\section{State security forces and firefighters}

Cleaning or maintenance personnel working in areas with patients COVID-19

Social services personnel serving the community or dependent persons

Personnel with habitual relationship with possible cases (continuous attention to the public)

Staff with sporadic relationship with possible cases

(non-continuous/sporadic attention to the public)

Personnel unrelated to possible cases (isolated or individual work)

\section{Total score of occupational risks}

*Risk Level Health sector (ref. Procedimiento de Actuación para los Servicios de Prevención de Riesgos Laborales frente a la exposición al SARS-COV-2. Disponible en:

https://www.mscbs.gob.es/profesionales/saludPublica/ccayes/alertasActual/nCov-China/documentos/Proteccion_Trabajadores_SARS-CoV-2.pdf).
Score

with rigorous compliance with preventive measures

with partial or total non-compliance with preventive measures

with rigorous compliance with preventive measures

with partial or total non-compliance with preventive measures

With rigorous compliance with preventive measures

Con Incumplimiento parcial o total de las medidas 1 preventivas

With rigorous compliance with preventive measures

With partial or total breach of preventive measures

With rigorous compliance with preventive measures

With partial or total breach of preventive measures

With rigorous compliance with preventive measures

With partial or total breach of preventive measures

With rigorous compliance with preventive measures

With partial or total breach of preventive measures

With rigorous compliance with preventive measures

With partial or total breach of preventive measures

No need for specific preventive measures (hygienic) 
Table 4. Preventive management at the workplace related to COVID-19 vulnerability.

\begin{tabular}{lll}
\hline & & Score \\
\hline Availability of Barrier Elements-PPE & Total availability & 0 \\
Preventive training & No availability or partial availability & 1 \\
& Regular and certified specific training and information & 0 \\
Health Surveillance & Irregular and/or non-protocol specific training and information & 1 \\
& Specific regular and protocolized health surveillance & 0 \\
Option to modify the conditions of the position Possible or not necessary & Specific surveillance of irregular and/or non-protocolized health \\
and/or job change options if necessary & Not possible or incomplete & 1 \\
Total score preventive management at the workplace & & 0 \\
\hline
\end{tabular}

streamline the process.

This is a proposal of protocol which has not been yet validated.

\section{Discussion}

Research related to the COVID 19 pandemic has led to a breakthrough in concepts that have been modified as the disease itself has done and its impact and evolution have been known. In the world of work, worker protection and transmission prevention mechanisms have been established, and have remarkably increased for workers considered as vulnerable, following official criteria established by the health authorities [35]. There are no similar protocols in the current literature to serve as a comparison, although the previously mentioned work by Marcus Lu partially addresses this topic, focusing on the risk from exposure of 100 well-known types of work and on a score based on three aspects: contact with others, physical proximity and risk of exposure to infection. In the protocol that we present here, 27 variables and subvariables are included, making it a comprehensive assessment of the worker and their work environment to determine the degree of vulnerability to COVID-19, which we hope can demonstrate its usefulness in subsequent testing, which is already taking place.

\section{Preventive Recommendations}

The main preventive recommendation regarding the protection of workers especially vulnerable to COVID-19 infection is to reduce exposure to risk:

- Conducting correct epidemiological surveillance based on the follow-up of cases and contacts that allows the early detection and control of infections in a coordinated way between occupational, primary, hospital health and public health organizations.

- Applying, within the scope of the specific powers of the Prevention Services, all the technical and health measures aimed at reducing the probability of contagion or limiting its consequences through: 1) training and specific information for workers and the implementation of prevention plans defined 
against COVID in companies; 2) adoption of organizational and preventive measures, both collective and individual, specific to COVID-19; 3) implementation of health surveillance procedures aimed at detection and protection of workers especially vulnerable to infection and the early management of possible cases in the workplace, especially in sectors of higher risk of contagion such as health and social health.

When the vulnerability of the worker recommends it, the change of job and the modifications in the working conditions would be the preventive priority options, with, if this was not possible, the medical leave for illness as a second option.

\section{Conclusions}

COVID-19 pandemic has created an enormous Public Health challenge and it has specifically affected work environments, with important Occupational Health repercussions. Acting based on preventive measures, each worker's vulnerability needs to be assessed and quantified.

For this vulnerability evaluation, a general approach including sociodemographic, clinical and labor variables is proposed, following the World Health Organization recommendation: "think innovatively and lead the promotion of health and risk prevention within the Public Health field, obtaining accurate information to prepare and reduce risk in affected people, their families, and their community [36]".

Our protocol quantifies occupational risks and preventive business management as well as individual risk factors, previous comorbidities and disease control. The combined sum of all of them will allow quantifying individual vulnerability score and guide subsequent preventive actions in Occupational Health.

\section{Conflicts of Interest}

The authors declare no conflicts of interest regarding the publication of this paper.

\section{References}

[1] Tran, B.X., et al. (2020) Characterize Health and Economic Vulnerabilities of Workers to Control the Emergence of Covid-19 in an Industrial Zone in Vietnam. Safety Science, 129, Article ID: 104811. https://doi.org/10.1016/j.ssci.2020.104811

[2] Baker, M.G., Peckham, T.K. and Seixas, N.S. (2020) Estimating the Burden of United States Workers Exposed to Infection or Disease: A Key Factor in Containing Risk of COVID-19 Infection. PLoS ONE, 15, e0232452. https://doi.org/10.1371/journal.pone.0232452

[3] Koh, D. (2020) Occupational Risks for COVID-19 Infection. Occupational Medicine, 70, 3-5. https://doi.org/10.1093/occmed/kqaa036

[4] Ahmad, A., Chung, R., Eckenwiler, L., Ganguli-Mitra, A., Hunt, M., Richards, R., et al. (2020) What Does It Mean to Be Made Vulnerable in the Era of COVID-19? The Lancet, 395, 1481-1482. https://doi.org/10.1016/S0140-6736(20)30979-X 
[5] Smith, J.A. and Judd, J. (2020) COVID-19: Vulnerability and the Power of Privilege in a Pandemic. Health Promotion Journal of Australia: Official Journal of Australian Association of Health Promotion Professionals, 31, 158-160. https://doi.org/10.1002/hpja.333

[6] Lu, M. (2020) The Front Line: Visualizing the Occupations with the Highest COVID-19 Risk.

https://www.visualcapitalist.com/the-front-line-visualizing-the-occupations-with-th e-highest-covid-19-risk

[7] Boccardi, V., Ruggiero, C. and Mecocci, P. (2020) COVID-19: A Geriatric Emergency. Geriatrics (Basel, Switzerland), 5, 24. https://doi.org/10.3390/geriatrics5020024

[8] Ministerio de Sanidad (2020) Manejo de la mujer embarazada y el recién nacido con COVID-19.

[9] Masmejan, S., Pomar, L., Lepigeon, K., Favre, G., Baud, D. and Rieder, W. (2020) COVID-19 and Pregnancy. Revue Médicale Suisse, 16, 944-946.

[10] Gebhard, C., Regitz-Zagrosek, V., Neuhauser, H.K., Morgan, R. and Klein, S.L. (2020) Impact of Sex and Gender on COVID-19 Outcomes in Europe. Biology of Sex Differences, 11, 29. https://doi.org/10.1186/s13293-020-00304-9

[11] Alsan, M., Stantcheva, S., Yang, D. and Cutler, D. (2020) Disparities in Coronavirus 2019 Reported Incidence, Knowledge, and Behavior Among US Adults. JAMA Netw Open, 3, e2012403. https://doi.org/10.1001/jamanetworkopen.2020.12403

[12] Informe no 14. Situación de COVID-19 en España a 24 marzo de 2020. https://www.isciii.es/QueHacemos/Servicios/VigilanciaSaludPublicaRENAVE/Enfer medadesTransmi-

sibles/Documents/INFORMES/Informes\%20COVID-19/Informe\%20n\%c2\%ba\%20 14.\%20Situaci\%c3\%b3n\%20de\%20COVID-19\%20en\%20Espa\%c3\%b1a\%20a\%2024 \%20marzo\%20de\%202020.pdf

[13] The Epidemiological Characteristics of an Outbreak of 2019 Novel Coronavirus Diseases (COVID-19)—China, 2020 [Internet]. http://weekly.chinacdc.cn/en/article/id/e53946e2-c6c4-41e9-9a9b-fea8db1a8f51

[14] Kattan, J., Kattan, C. and Assi, T. (2020) Do Checkpoint Inhibitors Compromise the Cancer Patients' Immunity and Increase the Vulnerability to COVID-19 Infection? Immunotherapy, 12, 351-354. https://doi.org/10.2217/imt-2020-0077

[15] Long, B., Brady, W.J., Koyfman, A. and Gottlieb, M. (2020) Cardiovascular Complications in COVID-19. The American Journal of Emergency Medicine, 38, 1504-1507. https://doi.org/10.1016/j.ajem.2020.04.048

[16] Driggin, E., Madhavan, M.V., Bikdeli, B., Chuich, T., Laracy, J., Biondi-Zoccai, G., et al. (2020) Cardiovascular Considerations for Patients, Health Care Workers, and Health Systems during the COVID-19 Pandemic. Journal of the American College of Cardiology, 75, 2352-2371. https://doi.org/10.1016/j.jacc.2020.03.031

[17] Zhou, F., Yu, T., Du, R., Fan, G., Liu, Y., Liu, Z., et al. (2020) Clinical Course and Risk Factors for Mortality of Adult Inpatients with COVID-19 in Wuhan, China: A Retrospective Cohort Study. The Lancet, 395, 1054-1062. https://doi.org/10.1016/S0140-6736(20)30566-3

[18] Zhang, W., Xu, Y.-Z., Liu, B., Wu, R., Yang, Y.-Y., Xiao, X.-Q., et al. (2014) Pioglitazone Upregulates Angiotensin Converting Enzyme 2 Expression in Insulin-Sensitive Tissues in Rats with High-Fat Diet-Induced Nonalcoholic Steatohepatitis. Scientific World Journal, 2014, Article ID: 603409.

https://doi.org/10.1155/2014/603409 
[19] Hussain, A., Vasas, P. and El-Hasani, S. (2020) Obesity as a Risk Factor for Greater Severity of COVID-19 in Patients with Metabolic Associated Fatty Liver Disease. Metabolism, 108, Article ID: 154256. https://doi.org/10.1016/j.metabol.2020.154256

[20] Muscogiuri, G., Pugliese, G., Barrea, L., Savastano, S. and Colao, A. (2020) Obesity: The “Achilles Heel” for COVID-19? Metabolism: Clinical and Experimental, 108, Article ID: 154251. https://doi.org/10.1016/j.metabol.2020.154251 https://www.metabolismjournal.com/article/S0026-0495(20)30115-3/abstract

[21] Samuels, J.D. (2020) Obesity and Severe COVID-19 Disease: A Strong Association. Obesity (Silver Spring).

[22] Pennington, E. (2020) Asthma Increases Risk of Severity of COVID-19. Cleveland Clinic Journal of Medicine. https://doi.org/10.3949/ccjm.87a.ccc002

[23] Johnston, S.L. (2020) Asthma and COVID-19: Is Asthma a Risk Factor for Severe Outcomes? Allergy, 75, 1543-1545. https://doi.org/10.1111/all.14348

[24] Tal-Singer, R. and Crapo, J.D. (2020) COPD at the Time of COVID-19: A COPD Foundation Perspective. Chronic Obstructive Pulmonary Disease, 7, 73-75. https://doi.org/10.15326/jcopdf.7.2.2020.0149

[25] Olds, J.L. and Kabbani, N. (2020) Is Nicotine Exposure Linked to Cardiopulmonary Vulnerability to COVID-19 in the General Population? The FEBS Journal. https://doi.org/10.1111/febs.15303

[26] Li, Y. and Xiao, S.-Y. (2020) Hepatic Involvement in COVID-19 Patients: Pathology, Pathogenesis, and Clinical Implications. Journal of Medical Virology. https://doi.org/10.1002/jmv.25973

[27] Feng, G., Zheng, K.I., Yan, Q.-Q., Rios, R.S., Targher, G., Byrne, C.D., et al. (2020) COVID-19 and Liver Dysfunction: Current Insights and Emergent Therapeutic Strategies. Journal of Clinical and Translational Hepatology, 8, 18-24. https://doi.org/10.14218/JCTH.2020.00018

[28] SICAM. Recomendaciones de la Sociedad de Inmunología de la Comunidad de Madrid para la prevención y manejo de la infección por el coronavirus (Covid-19) en pacientes con inmunodeficiencia. https://www.inmunologia.org/Upload/Documents/1/5/0/1506.pdf

[29] Ministerio de Sanidad. Procedimiento de actuación para los servicios de prevención de riesgos laborales frente a la exposición al SARS-CoV-2 [Internet].

https://www.mscbs.gob.es/profesionales/saludPublica/ccayes/alertasActual/nCov-C hina/documentos/PrevencionRRLL_COVID-19.pdf

[30] Canova, V., Lederer Schläpfer, H., Piso, R.J., Droll, A., Fenner, L., Hoffmann, T., et al. (2020) Transmission Risk of SARS-CoV-2 to Healthcare Workers-Observational Results of a Primary Care Hospital Contact Tracing. Swiss Medical Weekly, 150, w20257. https://doi.org/10.4414/smw.2020.20257

[31] El-Hage, W., Hingray, C., Lemogne, C., Yrondi, A., Brunault, P., Bienvenu, T., et al. (2020) Health Professionals Facing the Coronavirus Disease 2019 (COVID-19) Pandemic: What Are the Mental Health Risks? L'Encephale.

[32] Landrigan, P. (2020) Prevention of Work-Related Infection in the COVID-19 Pandemic. Journal of Occupational and Environmental Medicine.

[33] Ministerio de Sanidad. Guía de prevención y control frente al COVID19 en residencias de mayores y otros centros de servicios sociales de carácter residencial [Internet].

https://www.mscbs.gob.es/profesionales/saludPublica/ccayes/alertasActual/nCov-C hina/documentos/Residencias_y_centros_sociosanitarios_COVID-19.pdf

[34] Ministerio de Sanidad. Recomendaciones sobre el uso de mascarillas en la comuni- 
dad en el contexto de COVID-19 [Internet].

https://www.mscbs.gob.es/profesionales/saludPublica/ccayes/alertasActual/nCov-C hina/documentos/Recomendaciones_uso_mascarillas_ambito_comunitario.pdf

[35] Procedimiento de Actuación para los Servicios de Prevención de Riesgos Laborales frente a la exposición al SARS-COV 2.

https://www.mscbs.gob.es/profesionales/saludPublica/ccayes/alertasActual/nCov-C hina/documentos/Proteccion_Trabajadores_SARS-CoV-2.pdf

[36] The Lancet (2020) Redefining Vulnerability in the Era of COVID-19. The Lancet, 395, 1089. https://doi.org/10.1016/S0140-6736(20)30757-1 